The Queensland Occupational Therapy Fieldwork Collaborative (QOTFC), which was founded in 2004, includes representatives from universities, practising occupational therapists, professional registration bodies and key employers, and aims to promote a shared vision for the future of practice placement education (fieldwork) in Queensland, Australia. Strategic alliances between key occupational therapy stakeholders were fostered by the QOTFC to address a shortfall of occupational therapy practice placement education opportunities in Queensland. This paper describes a project that aimed to engage occupational therapy clinicians in localised 'hubs' across the state of Queensland, with a view to solving practice placement shortfalls. The project evaluation and outcomes are discussed. The outcomes indicated that ownership of practice placement education across the entire profession is critical, and can be achieved through a strategic and a collective focus of key stakeholders working collaboratively with local professionals.

\title{
Evaluation of a Collaborative Project to Engage Occupational Therapy Clinicians in Promoting Practice Placement Education
}

\author{
Sylvia Rodger, ${ }^{1}$ Yvonne Thomas, ${ }^{2}$ Cate Fitzgerald, ${ }^{1}$ David Dickson, ${ }^{3}$ Cathy McBryde, ${ }^{4}$ \\ Ann Edwards, Jacqui Broadbridge ${ }^{6}$ and Rachel Hawkins ${ }^{7}$
}

\section{Introduction}

A collaborative project focused on assisting clinicians to develop localised solutions to enhance practice placement education (fieldwork)* opportunities. The evaluation strategy, which aimed to investigate the delivery, impact and sustainability of the project, is described. The results of this evaluation highlight the applicability of a collaborative process that focuses on supporting community-built solutions to multilayered and complex professional issues.

\footnotetext{
${ }^{1}$ The University of Queensland. ${ }^{2}$ James Cook University, Townsville, Queensland.

${ }^{3}$ Mater Private Hospital (Rehabilitation Unit), Brisbane, Queensland.

${ }^{4}$ Paediatric Occupational Therapy Services, Brisbane, Queensland.

${ }^{5}$ Mater Health Services, Brisbane, Queensland. ${ }^{6}$ CRS Australia, Queensland.

7WorkCover Queensland, Brisbane, Queensland.
}

Corresponding author: Associate Professor Sylvia Rodger, Division of Occupational Therapy, School of Health and Rehabilitation Sciences, The University of Queensland, Brisbane, Queensland 4072, Australia. Email: s.rodger@uq.edu.au

Submitted: 15 November 2007.

Accepted: 1 May 2008.

Key words: Practice education, fieldwork, student education, workforce. Reference: Rodger S, Thomas Y, Fitzgerald C, Dickson D, McBryde C, Edwards A, Broadbridge J, Hawkins R (2008) Evaluation of a collaborative project to engage occupational therapy clinicians in promoting practice placement education. British Journal of Occupational Therapy, 71(6), 248-252.

\section{Background}

For reasons that vary by country and by region, sourcing practice placements for occupational therapy students has become increasingly difficult in recent years (Thomas et al 2007). This problem has been experienced globally and has been attributed by various authors to factors such as increased enrolments in allied health education programmes (Casares et al 2003, Thomas et al 2005); changes in employment patterns (Jones et al 1998); increased demands on clinicians (Steele-Smith and Armstrong 2001, Casares et al 2003); industrial issues; fiscal constraints; and a movement away from the government sector towards private practice (Thomas et al 2005).

Pressure on the number of practice placements available has necessitated greater creativity by universities responsible for student practice placement education. Universities have sought to increase the number of practice placements available by exploring non-traditional placement options (Fisher and Savin-Baden 2002a, 2002b, Thomas et al 2005), such as project-focused placements (Fortune et al 2006), role-emerging placements (Bossers et al 1997) and alternative supervision models including shared supervision and project placements (Thomas et al 2005).

*The collaborative project used the term 'fieldwork', which has been replaced with 'practice placement education' in line with current terminology in the United Kingdom. 


\section{The Engaging the Clinicians project}

Funded by Queensland Health, the Engaging the Clinicians project brought together occupational therapists interested in practice placement education to influence local regions to provide, increase and sustain practice placement opportunities for occupational therapy students. The project was conducted from July 2006 to June 2007. A key feature of the project was the development of a network of occupational therapy professional interest groups, that is, 'hubs'. Hubs were defined by specific geographical locations or by specialty areas of practice (for example, mental health, private practice and paediatrics). Each hub was invited to nominate two hub champions, with whom the QOTFC would communicate. A project officer was employed by the QOTFC to coordinate and manage the project. The hub champions consulted with occupational therapists regarding local barriers and enablers for enhancing practice placement opportunities in their hubs.

A practice placement education symposium brought together the hub champions, the QOTFC members, university staff and invited guests who could support and provide resources to the hub champions. At the symposium, the hub champions presented information about local barriers and enablers to practice placement education, and key themes were thus identified. These themes formed the basis of solution-focused discussion groups and action planning at the symposium. One of the key outcomes of the symposium was the development of localised action plans to address the identified barriers in each hub. Ongoing support to the hub champions was provided by the project officer.

In response to the identified needs of the hub champions, two resources were developed by the QOTFC to support practice placement education. First, a Clinical Educator's Resource Kit was developed as a web-based resource (http//www.qotfc.edu.au). This website provides information regarding pre-placement considerations; setting up and sustaining a positive practice placement; approaches to practice placement education; feedback and evaluation; and working with students who are experiencing difficulties. Second, in recognition of the financial burden to students of travelling to and being accommodated in rural and remote areas, guidelines for a placement grant scheme were developed. This resource now provides templates for local therapists to assist with gaining financial support from local business and service groups for student placements in their local or regional area.

The remainder of this paper outlines the project evaluation and outcomes and provides a discussion of the process undertaken to develop and complete the project.

\section{Project evaluation}

\section{Method}

\section{Project participants}

At the commencement of the project, 21 hub champions were identified and invited to participate in the practice placement education symposium. These participants had varied years of experience and practice specialties, and represented a wide range of regions throughout the state of Queensland.

\section{Measures}

Telephone interview: A structured telephone survey was developed by members of the QOTFC to gain detailed feedback from the hub champions about the activities and actions undertaken within their hubs, as well as their views about the success and outcomes of the project as a whole. The telephone survey aimed to elicit comments about:

1. The main issues that had had an impact on hub membership and activities over the last 12 months

2. The type of support that the hub champions had received from the QOTFC project officer

3. The experience of being involved in this project as a hub champion

4. Whether the QOTFC project achieved its aims or not

5. Any observed changes in enablers and barriers to the provision of occupational therapy student practice placements in their hub

6. Project sustainability.

The first five topics were covered using open-ended questions, with project sustainability addressed by asking participants to respond on a five-point Likert scale (response options ranging from strongly disagree $=1$ to strongly agree $=5$ ) to 10 sustainability items read out by the interviewer. These can be viewed in Table 3 under the discussion of results.

\section{Procedure}

The Behavioural and Social Sciences Ethical Review Committee at The University of Queensland approved the study. The hub champions provided written informed consent to participate. In order to collect objective and independent information about the project, an independent evaluator administered the telephone interview in the final stages of the project.

\section{Analysis}

With respect to the 10 sustainability items, the agree and strongly agree categories were collapsed. The responses are reported in terms of the percentage of participants who agreed or strongly agreed with questions. The responses to the open-ended questions in the telephone interview were categorised and coded according to emerging themes, using standard content analysis.

\section{Results}

\section{Telephone interview}

Ten hub champions (48\%) were interviewed post-project, with the majority reporting that the project had engaged local therapists and had increased interest in practice placement education in their area. The majority of the 


\begin{tabular}{|c|c|c|c|}
\hline $\begin{array}{l}\text { Telephone survey questions } \\
\text { Aims of project }\end{array}$ & $\begin{array}{l}\text { Hub/project } \\
(\mathrm{n}=10)\end{array}$ & $\begin{array}{c}\text { Agree or strongly agree } \\
\text { that aim achieved }\end{array}$ & $\begin{array}{l}\text { Unsure or disagree } \\
\text { that aim achieved }\end{array}$ \\
\hline Promote engagement with a shared vision for the future of & For hub .......... & $\ldots 90 \% \ldots$ & $\ldots 10 \% \ldots$ \\
\hline occupational therapy practice placement education* & For project overall & $\ldots \ldots \ldots \ldots . .90 \% \ldots$ & $\ldots \ldots .10 \% \ldots$ \\
\hline Promote awareness of proactive occupational therapy responses & For hub....... & $\ldots 90 \%$ & .....10\%.. \\
\hline to support practice placement education & For project overall & $\ldots \ldots \ldots \ldots . . .70 \%$... & .....30\%.. \\
\hline Continue to develop ownership in collaborative problem solving & For hub..... & .....90\% . & .....10\%. \\
\hline of practice placement education issues & For project overall & $\ldots \ldots \ldots \ldots . . .60 \%$ & $\ldots \ldots \ldots . . .40 \%$ \\
\hline \multirow[t]{2}{*}{ Engage early adopters in project planning for positive change } & For hub ............ & $\ldots 90 \%$. & $\ldots . .10 \%$. \\
\hline & For project overall & $\ldots . .60 \% \ldots$ & $\ldots . . .40 \%$ \\
\hline \multirow{2}{*}{$\begin{array}{l}\text { Develop and implement plans for increasing involvement and action } \\
\text { of occupational therapy across the state }\end{array}$} & For hub.. & $\ldots 70 \%$. & $\ldots 30 \%$. \\
\hline & For project overall & $\ldots . . .70 \%$ & ......30\%.. \\
\hline Generate additional practice placements across government and & For hub.. & $\ldots 40 \%$. &. $.60 \%$ \\
\hline non-government agencies & For project overall & $\ldots \% \ldots \ldots$ & $\ldots \ldots . .100 \% \ldots$ \\
\hline \multirow[t]{2}{*}{ Actively progress alternative models of supervision } & For hub.. & $\ldots 60 \%$ &. $.40 \%$ \\
\hline & For project overall & $\ldots 30 \%$ &. $.70 \%$ \\
\hline
\end{tabular}

*The project aims, individual outcomes (Table 2) and sustainability items (Table 3) used the term 'fieldwork', which has been replaced with 'practice placement education'.

participants perceived that the project achieved six out of the seven aims in the hubs and five out of the seven aims for the project overall (see Table 1). The two aims that were not considered to have been met (as yet) were 'generate additional practice placements' and 'actively progress alternative models of supervision'. Several participants commented that it was too soon for many of the targeted changes to have occurred and that these would likely transpire over time.

Other project strengths reported by the hub champions were an increased understanding and awareness of practice placement education provision, the ability to see the bigger

\section{Table 2. Individual outcomes reported by hub champions at project completion}

- Use of alternative models to practice placement provision, including role-emerging/project placements, the collaborative approach and shared placements

- Identification of additional practice placement options within the region and linking and supporting therapists during placements

- Establishment of student tutorial networks across regional facilities and coordinating shared student learning opportunities

- Creation of promotional videos of their regions to attract potential practice placement students

- Provision of local support for first-time practice placement educators

- The establishment of regional occupational therapy networks

- Preparation of shared student orientation resources for use by all facilities, including an orientation to the region for the use of practice placement students

- Review of opportunities for financial assistance and accommodation for students undertaking regional practice placements

- Development of a pre-learning package and a quiz to determine the core skills students bring with them to practice placements. picture across Queensland, the opportunity to network and share ideas, and an increased sense of ownership of student education.

A range of individual strategies to combat practice placement education barriers was developed and the outcomes were achieved (see Table 2). Several respondents reported that a variety of supervisory models was being planned or implemented in their hubs, including non-traditional models such as shared supervision and project placements. This was associated with being better informed about the alternative options for supervision of students, realising the potential of some models to reduce the pressure on practice placement educators and recognising the role of part-time occupational therapists in practice placement education.

\section{Sustainability items}

A majority of the participants generally agreed or strongly agreed that the outcomes were sustainable beyond the life of the project. However, some felt that it was too soon for the project to have realised its aim of significantly increasing the number of placements in each hub (see Table 3). In particular, the web-based resources provided a means for the ongoing provision of information and resources to assist practice placement educators.

The hub champions suggested a range of supports that they considered necessary for the hubs in order to provide sustainable practice placement education opportunities. 'Face-to-face support' (for example, from a visiting university representative or a local coordinator) was suggested by half the respondents, in order to continue with the development of the hubs, to assist in organising and developing new placements, and to support the therapists who lacked the confidence to 


\begin{tabular}{|c|c|c|}
\hline Sustainability indicators/items & $\begin{array}{c}\text { Agree or } \\
\text { strongly agree }\end{array}$ & $\begin{array}{r}\text { Unsure or } \\
\text { disagree }\end{array}$ \\
\hline The project was effective (visible outcomes and acknowledgement). & $\ldots 90 \% \ldots$ &. $.10 \%$ \\
\hline The project aims were integrated with other hub activities ....................... & $\ldots . . . .80 \% \ldots \ldots \ldots . . . .$. & ......20\% ....... \\
\hline There was a favourable hub environment for outcomes to be achieved beyond the project end date ........... & $\ldots \ldots \ldots . . .70 \% \ldots \ldots \ldots$ & $\ldots . . .30 \% \ldots . .$. \\
\hline Hubs had ongoing support to continue to advocate for sustainable opportunities for practice placements... & $\ldots . .80 \% \ldots$ &. $.20 \%$ \\
\hline Hubs felt well supported by the project officer ....... &. $.90 \% \ldots \ldots$ &. $.10 \%$ \\
\hline 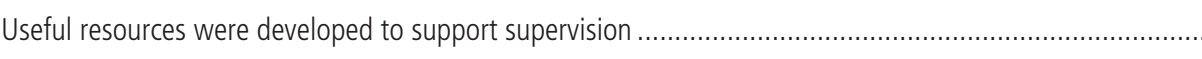 & 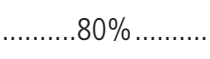 & $\ldots 20 \%$ \\
\hline The hubs accessed the Clinical Educator's Resource Kit and found it to be a useful resource .................... & $\ldots . .60 \% \ldots . . . .$. & $\ldots 40 \%$ \\
\hline The range of practice placement options had increased during the project................................ & 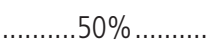 & $\ldots . .50 \%$ \\
\hline The number of practice placements had increased in the hubs during the project... & $\ldots . .30 \% \ldots$ & $\ldots 70 \%$ \\
\hline The outcomes of the project were well integrated in their hubs .......... & $\ldots . . .30 \% \ldots \ldots . . .$. &. $.70 \%$ \\
\hline Alternative models of supervision had been trialled in hubs to date.. & $\ldots 30 \%$.. & $\ldots 70 \%$. \\
\hline
\end{tabular}

engage in supervision or were having difficulties with students. Other suggestions included an increased sharing of success stories, regular visits from universities and the provision of organisational support (such as office space and resources).

\section{Discussion}

The evaluation of the Engaging the Clinicians project highlights the need to address practice placement education challenges in a coordinated and localised manner. Solutions must reflect the identified needs in each local geographical area, and cannot be determined by one centralised body alone. By engaging clinicians in determining and proposing solutions to local problems, shared ownership was fostered.

Using community development theory (Kenny 1999), the Engaging the Clinicians project aimed to encourage participatory action across the professional community. Rather than developing and instigating state-wide plans and procedures using a top-down, uniform approach, the QOTFC recognised the need to ensure small-scale and targeted changes at the local level. Integral to this process was the concept of empowerment and capacity building within the profession. The empowerment of the hub champions was afforded through the acknowledgement of their key role in directing the changes and actions within their local groups.

Sustainability was more obviously achieved in those hubs where there was strong cohesion and greater workforce stability. In hubs where staff recruitment and retention were challenging (that is, rural and remote locations), hub cohesion was more problematic. By resourcing rural and remote locations with two hub champions (as opposed to just one in urban areas), these areas managed to maintain involvement in the project, despite a number of resignations over the 12-month period during which the project was conducted. The participants recommended that these hub positions should be funded, rather than being voluntary.
This recommendation has been endorsed by the QOTFC and proposed to Queensland Health for consideration.

Establishing a change in the culture of practice placement education by developing new approaches and models was anticipated to occur over a longer period of time than the 12 -month project timeframe. As previously stated, the QOTFC identified and responded to the need for additional practice placement education resources that aimed to support practice education. Ongoing support and collaboration between the universities and the hub champions, as well as an effective feedback loop to the QOTFC, will assist with the sustainability of project outcomes.

\section{Limitations and conclusions}

With the $48 \%$ response rate in the final evaluation, it is impossible to determine if these results truly represent the experiences and perceptions of all hub champions. The project was based throughout the state of Queensland, Australia, and therefore represents a range of issues and solutions that is relevant to this unique context. The purpose of this paper is to outline the project's evaluation, which highlighted the relevance of a community development approach to meeting practice placement education challenges. By working as a collaborative of key stakeholders, the QOTFC has thus far provided a strong and united professional voice. The group is well informed regarding the multiple levels of political interest in ensuring educational opportunities for occupational therapists in Queensland. By gaining government funding, the QOTFC demonstrated the profession's commitment to being proactive in finding solutions for the practice placement shortages.

It is clear from this project that local areas need local solutions. Although the QOTFC has developed a number of resources, there is a strongly identified need for localised actions at individual, organisational and regional levels. By acknowledging local needs, appropriate solutions to practice placement education challenges can be identified and supported strategically. 


\section{Acknowledgements}

The QOTFC gratefully acknowledges funding from Queensland Health to enable the development of practice placement education resources, as well as the conduct of the project and project evaluation. We would like to acknowledge ongoing support from Libby Carr, Allied Health Adviser, Queensland Health, and the Health Advisory Unit.

\section{References}

Bossers AM, Cook JV, Polatajko HJ, Laine C (1997) Understanding the role-emerging fieldwork placement: a qualitative inquiry. Canadian Journal of Occupational Therapy, 64(2), 70-81.

Casares GS, Bradley KP, Jaffe LE, Lee GP (2003) Impact of the changing health care environment on fieldwork education. Journal of Allied Health, 32(4), 246-51.

Fisher A, Savin-Baden M (2002a) Modernising fieldwork, part 1: realising the potential. British Journal of Occupational Therapy, 65(5), 229-36.

Fisher A, Savin-Baden M (2002b) Modernising fieldwork, part 2: realising the new agenda. British Journal of Occupational Therapy, 65(6), 275-82.
Fortune T, Farnworth L, McKinstry C (2006) Project-focussed fieldwork: core business or fieldwork fillers? Australian Occupational Therapy Journal, 53(3), 233-36.

Jones A, Yeung E, Webb C (1998) Tripartite involvement in health care clinical education. Journal of Allied Health, 27, 97-102.

Kenny S (1999) Developing communities for the future: community development in Australia. Melbourne: Nelson.

Steele-Smith S, Armstrong M (2001) 'I would take more students but ...' : Student supervision strategies. British Journal of Occupational Therapy, 64(11), 549-51.

Thomas Y, Penman M, Williamson P (2005) Australian and New Zealand fieldwork: charting the territory for future practice. Australian Occupational Therapy Journal, 52, 78-81.

Thomas Y, Dickson D, Broadbridge J, Hopper L, Hawkins R, Edwards A, McBryde C (2007) Benefits and challenges of supervising occupational therapy fieldwork students: supervisors' perspectives. Australian Occupational Therapy Journal, 54(s1), s2-s12 doi:10.1111/j.1440-1630.2007.00694.x

\section{Focus on Research}

Theses donated to the COT Library are available for loan, but are not downloadable. Please contact the Library for details.

\section{Jill Blount}

The use of occupationally focused assessment tools: the practice of occupational therapists working with adults with learning disabilities in the UK.

University of Derby, 2007. MSc in Occupational Therapy (Community).

This study investigates the occupationally focused assessment tools used by occupational therapists working with adults with learning disabilities. It focuses on whether standardised or non-standardised tools are used, the factors influencing the choices of assessment tool, and whether any modifications are carried out to the tools to enable them to be used more easily with the client group. Details are provided of the background to the study, the methodology and the ethical considerations. The research design is a cross-sectional descriptive study, using a postal questionnaire for data collection. The questionnaire used both closed questions, which produced quantitative data, and free text answers to open questions. Using the posteriori method, the qualitative data were subject to content and thematic analysis as a result of categories that developed as the data were collected.

Out of 220 questionnaires sent out, 103 (46.8\%) were returned and 100 (45\%) were deemed eligible. The findings indicated that 92 of the 100 used occupationally focused assessment tools, with 55 using both standardised and non-standardised. The most frequently used standardised assessments were the MOHOST ( $n=54 / 54 \%)$ and the AMPS $(n=48 / 48 \%)$, with initial assessments $(n=43 / 48 \%)$ and independent living skills/ADL assessments $(n=60 / 67 \%)$ being the most frequent non-standardised assessments.

The client's needs and abilities have the most influence on the choice of assessment, along with being trained in the use of a standardised tool. The respondents reported that the non-standardised assessments were more flexible but were not able to produce adequate outcome measures. The modifications reported, to both standardised and non-standardised assessments, were simplifying the language and the use of photographs, pictures and symbols to aid comprehension and communication with the clients.

The findings indicate an increased uptake of standardised assessments from previous studies, and no previous study has examined the modifications made to the standardised assessments or acknowledged that this practice takes place, rendering the standardised assessments invalid. These modifications indicate that many therapists still feel that there is a lack of suitable standardised assessments for this client group, which is consistent with previous studies. The study produced new information on the type of modifications that therapists make to standardised and non-standardised assessments in order to make them more suitable for the client group. It is suggested that further research on the need for specific assessment tools for this complex client group would be beneficial and aid the development of suitable standardised occupationally focused assessment tools. 